\title{
Drug discovery for Chagas disease should consider Trypanosoma cruzi strain diversity
}

\author{
Bianca Zingales ${ }^{1 /}{ }^{+}$, Michael A Miles ${ }^{2}$, Carolina B Moraes ${ }^{3}$, Alejandro Luquetti ${ }^{4}$, \\ Felipe Guhl' ${ }^{5}$ Alejandro G Schijman ${ }^{6}$, Isabela Ribeiro
}

\begin{abstract}
${ }^{1}$ Instituto de Química, Universidade de São Paulo, São Paulo, SP, Brasil ${ }^{2}$ Faculty of Infectious and Tropical Diseases, London School of Hygiene and Tropical Medicine, London, UK ${ }^{3}$ Laboratório Nacional de Biociências, Centro Nacional de Pesquisa em Energias e Matérias, Campinas, SP, Brasil ${ }^{4}$ Hospital das Clínicas, Universidade Federal de Goiás, Goiânia, GO, Brasil ${ }^{5}$ Centro de Investigaciones en Microbiología y Parasitología Tropical, Facultad de Ciencias, Universidad de los Andes, Bogotá, Colombia ${ }^{6}$ Instituto de Investigaciones en Ingeniería Genética y Biología Molecular-Consejo Nacional de Investigaciones Científicas y Técnicas, Buenos Aires, Argentina ${ }^{7}$ Drugs for Neglected Disease initiative, Geneva, Switzerland
\end{abstract}

This opinion piece presents an approach to standardisation of an important aspect of Chagas disease drug discovery and development: selecting Trypanosoma cruzi strains for in vitro screening. We discuss the rationale for strain selection representing T. cruzi diversity and provide recommendations on the preferred parasite stage for drug discovery, T. cruzi discrete typing units to include in the panel of strains and the number of strains/clones for primary screens and lead compounds. We also consider experimental approaches for in vitro drug assays. The Figure illustrates the current Chagas disease drug-discovery and development landscape.

Key words: in vitro drug screening - T. cruzi genetic diversity - guidelines

Chagas disease is a chronic, systemic, parasitic infection caused by the protozoan Trypanosoma cruzi. According to estimates by the Pan American Health Organization and the World Health Organization (WHO), 7.7-10 million people are chronically infected with $T$. cruzi and 10,000-14,000 deaths per year are caused by Chagas disease (Schofield et al. 2006, WHO 2013). Approximately $60-70 \%$ of the chronic patients have no clinical symptoms (indeterminate form), whereas $30-40 \%$ either have or will develop cardiomyopathy, digestive megasyndromes or both. Chagas disease ranks among the world's most neglected diseases and is considered to be the parasitic infection with the greatest socioeconomic impact in Latin America, being responsible for an estimated US\$ 1.2 billion in lost productivity annually (WHO 2012). In the last four decades, controlling vector and blood transfusion-transmission of $T$. cruzi has been successful in several endemic countries. However, other transmission mechanisms, such as congenital, transplantation and oral, may sustain infection. Furthermore, population migration has caused Chagas disease to be a worldwide public health issue.

New treatments for Chagas disease are urgently needed. The only two drugs available, benznidazole (BZ) and nifurtimox (NF), require prolonged treatment,

doi: 10.1590/0074-0276140156

+Corresponding author: bszodnas@iq.usp.br

Received 6 May 2014

Accepted 27 June 2014 are often poorly tolerated and have variable efficacy in the chronic phase of the disease, which is the predominant clinical presentation encountered (Rassi Jr et al. 2012). The reasons for treatment failures are unknown, but may be due to different treatment evaluation methods, incomplete treatment administration, variable drug susceptibility among $T$. cruzi strains and characteristics of the host's immune system (Urbina 2010). Nevertheless, several non-randomised clinical studies demonstrate the efficacy of etiological treatment to reduce antibody titres and the progression of chronic Chagas heart disease (Sosa-Estani et al. 2009). Two double-blind, placebo-controlled clinical trials with a large cohort of patients, TRAENA and BENEFIT (Figure), are assessing whether BZ therapy improves prognosis for patients with chronic Chagas disease.

Following years of little progress in the research and development (R\&D) of new drugs to treat Chagas disease, significant advances have recently been made with increased collaborations and partnerships in drug discovery and lead optimisation (Buckner 2011, WHO 2012) (Figure). Upstream R\&D activities include efforts to increase the harmonisation and standardisation of drug screening protocols and the development of high throughput methodologies for in vitro testing. Novel chemical classes have shown promising activity against $T$. cruzi. Two Phase IIa clinical trials evaluating antiparasitic activity of the ergosterol biosynthesis inhibitors posaconazole and ravuconazole (E1224, prodrug) in chronic patients have recently been concluded (DNDi 2013, Molina et al. 2014), but with disappointing results. A cysteine protease (cruzipain) inhibitor (vinylsulfone derivative K777), the 5-nitroimidazole fexinida- 
zole and a nontoxic fungicide fenarimol, among others, are in pre-clinical studies (Figure). Importantly, alternative treatment regimens are being considered, including combination therapies with available and new anti-T. cruzi drugs (Benaim et al. 2006, Bustamante et al. 2013, Diniz et al. 2013), with potential for synergy, better tolerability, avoidance of drug resistance and to provide backup drugs when resistance emerges.

T. cruzi genetic diversity - Recent new in vitro and in vivo drug screening protocols have included reference strains of T. cruzi. The selection of these strains has been largely pragmatic, based on availability and historical experience. However, previous experimental evidence in a murine model indicated that BZ and NF may exhibit a broad range of divergent activities against different T. cruzi strains (Filardi \& Brener 1987, Neal \& van Bueren 1988). A recent study described large variations in the response to ergosterol biosynthesis inhibitors in in vitro assays against a panel of $T$. cruzi strains and clones belonging to different genetic lineages (see below); in contrast, BZ and NF did not differ significantly in their efficacy against the same panel of strains and clones (Moraes et al. 2014). Whether the experimental data obtained in mice and in vitro with $T$. cruzi strains correspond to the response to drugs in human hosts has not yet been established, partially because definitive criteria for curing Chagas disease are lacking. Nevertheless, the available evidence supports the proposition that assessing the activity of new compounds against a representative panel of strains is essential.

This proposition takes into consideration the remarkably diverse multiplicity of $T$. cruzi genotypes and phenotypes (Miles et al. 2009, Guhl \& Ramírez 2011, Zingales et al. 2012), designated by consensus as comprising six $T$. cruzi discrete typing units TcI-TcVI (Zingales et al. 2009). The term "discrete typing unit" (DTU) was proposed to describe sets of stocks that are genetically more similar to one another than to any other stock and are identifiable by common molecular markers (Tibayrenc 1998).

\section{Chagas Disease Drug Discovery and Development Landscape}

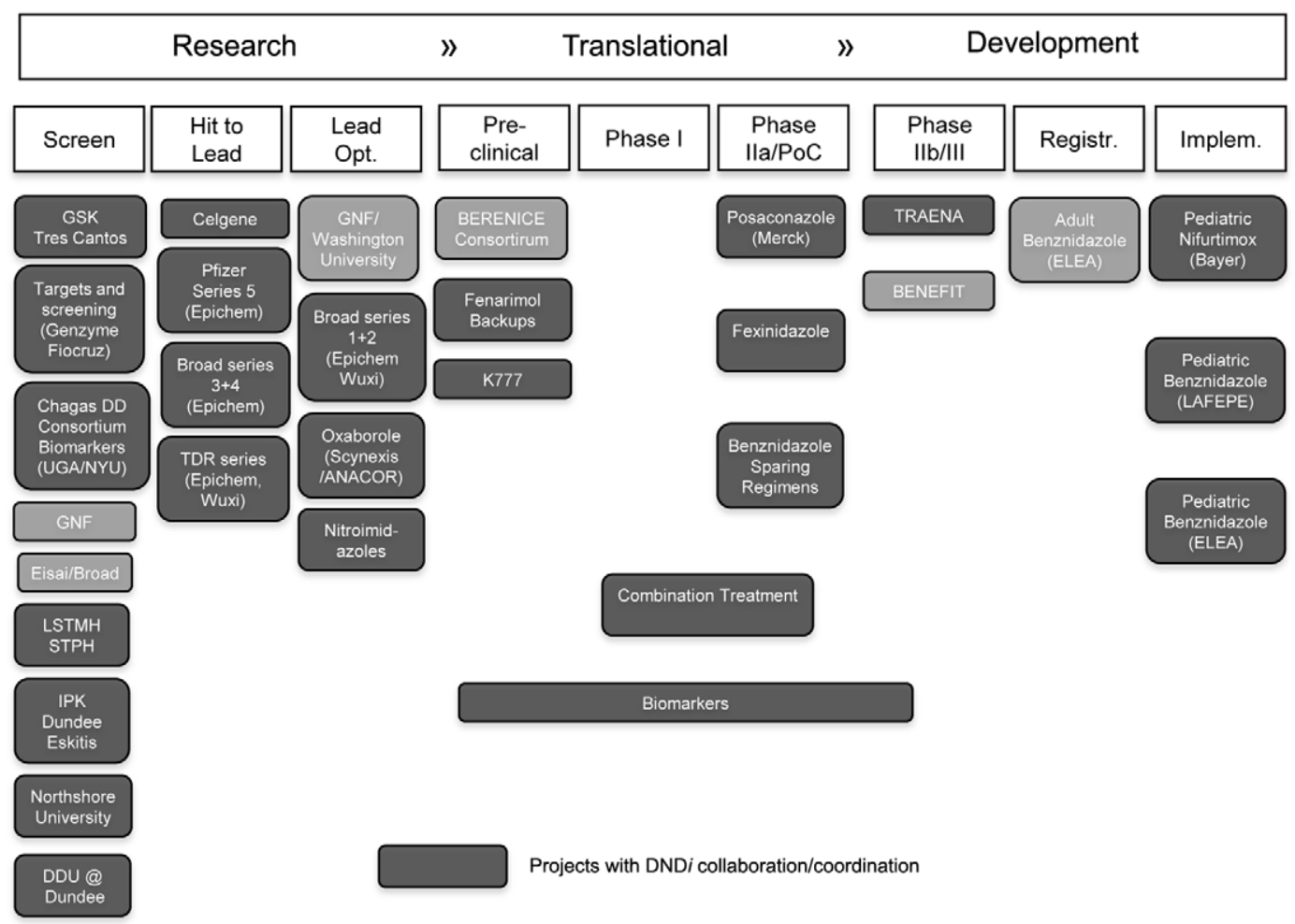

Chagas disease drug discovery and development landscape in 2013/2014. Research activities: public and private partners are engaged in the screening of chemical libraries, hit to lead and lead optimisation of new series for Chagas disease treatment; Translational activities: pre-clinical studies, Phase I and IIa studies with new compounds are underway; Development activities: two double-blind, placebo-controlled clinical trials are testing the potential beneficial effects of benznidazole (BZ) in chronic Chagas disease. The Argentine company Elea Laboratories is manufacturing the generic version of BZ under the tradename Abarax. Paediatric formulations of BZ and nifurtimox are being implemented. BENEFIT: Benznidazole Evaluation for Interrupting Trypanosomiasis; BERENICE: Benznidazole and Triazole Research Group for Nanomedicine and Innovation on Chagas Disease; Broad: Broad Institute; DDU@Dundee: Drug Discovery Unit at Dundee University; DNDi: Drugs for Neglected Diseases initiative; GNF: Genomics Institute of the Novartis Research Foundation; IPK: Institute Pasteur Korea; LSTMH: London School of Tropical Medicine \& Hygiene; NYU: New York University; STPH: Swiss Tropical and Public Health Institute; TRAENA: Tratamiento con Benznidazol en pacientes Adultos con Enfermedad de Chagas Crónica; UGA: University of Georgia. 
TABLE

Summary of disease associations, geographical distribution, ecotope and host of Trypanosoma cruzi discrete typing units TcI to TcVI ${ }^{a}$

TcI

TcIV

$\mathrm{TcV}$ and $\mathrm{TcVI}$
The main agent of Chagas disease in the northern part of Latin America and in the Amazon Region. Found widely in silvatic cycles elsewhere. Many silvatic reservoirs, especially opossums

(Didelphis). Genetically highly diverse.
TcIII

\section{TcII}

The principal agent of Chagas disease in Atlantic and Central Brazil. Occasionally found further North. Several silvatic reservoirs have been reported, but wild host species are not fully known. (Dasypus) in South America. Some isolates have been found virulent to mice. Genetically diverse.

Secondary agent of Chagas disease in Venezuela. Arboreal (primates, raccoons) and terrestrial reservoirs. Silvatic, along with TcI, in North America.

Common agents of Chagas disease in the Gran Chaco/Southern Cone region. Rarely silvatic, thus reservoirs, if any, are poorly known. Possible anthropogenic or peridomestic origins. Both genetically conserved. Recent hybrids of TcII and TcIII.

a: information compiled from Miles et al. (2009), Guhl and Ramírez (2011) and Zingales et al. (2012).

Currently, several typing approaches for DTU assignment of T. cruzi populations are available and manageable in laboratories in endemic areas (Zingales et al. 2012). T. cruzi DTUs have distinct, but not exclusive ecological and epidemiological associations (Table). Correlation of the clinical presentation of chronic Chagas disease with DTUs is circumstantial, but not proven and is complicated by the occurrence of mixed infections, sequestration of DTUs in tissues and complex interactions with the host immune response (Vago et al. 2000, Miles et al. 2009, Urbina 2010, Zingales et al. 2012). Chagasic cardiomyopathy and ECG abnormalities occur throughout endemic regions; megaoesophagus and megacolon are considered to be common in the Southern Cone and rare north of the Amazon (Miles et al. 2009, Guhl \& Ramírez 2011, Zingales et al. 2012).

The Drugs for Neglected Diseases initiative (DND $i$ ) has been interested in understanding the impact of T. cru$z i$ genetic diversity for R\&D of new treatments for Chagas disease. Accordingly, a group of experts convened during the Chagas Clinical Research Platform Meeting, sponsored by DND $i$ on 23 September 2012 in Rio de Janeiro, Brazil, to establish criteria for the selection of T. cruzi strains for drug screening and to issue recommendations.

In arriving at the consensus recommendations, the following were considered:

Characteristics of T. cruzi developmental forms The T. cruzi life cycle consists of three main developmental forms: the "epimastigote", which proliferates in the gut of triatomine vectors, the "trypomastigote", a non-dividing form that has the capacity to invade mammalian cells and differentiates into intracellular amastigotes, and the "amastigote", which multiplies by binary fission in the cytoplasm of infected cells. Trypomastigotes arise both in the hindgut of the triatomine vector, termed metacyclic (infective) trypomastigotes and in the mammalian host. After several cycles of division, intracellular amastigotes transform to trypomastigotes, which destroy the cell and emerge either to invade a new host cell or to reach the bloodstream, from which they may be ingested by the insect vector. In the chronic phase of Chagas disease, parasitaemia is usually low and it is difficult to detect and isolate T. cruzi.

Nomenclature of T. cruzi populations - Primary isolate: a parasite population collected from an infected source (mammalian host or insect vector) and inoculated into culture medium or susceptible experimental animals; stock: a population derived from the primary isolate, whose properties have not been studied; strain: a population with characterised biological and/or biochemical parameters, maintained by serial passage in laboratory animals or in culture; clone: a population derived from a single organism. A population in which all individuals are considered to be genetically indistinguishable is referred to as a monoclonal population, whereas a polyclonal population is a population composed of individuals who are genetically dissimilar. Numerous reports indicate that natural hosts and vectors may be infected with polyclonal T. cruzi populations.

DTUs and human infection - As shown in Table, DTUs TcI, TcII, TcV and TcVI are agents of human disease with disparate prevalence in different regions of Latin America (Miles et al. 2009, Guhl \& Ramírez 2011, Zingales et al. 2012). TcI is a major human infection agent in Amazonia, the Andean Region, Central America and Mexico. Clinical presentations include chagasic cardiomyopathy and severe cases of meningoencephalitis in immunocompromised hosts. Recent studies have identified a divergent group within TcI, named $\mathrm{TcI}_{\mathrm{DOM}} . \mathrm{TcI}_{\mathrm{DOM}}$ is associated with a significant proportion of human TcI infections from Venezuela to northern Argentina (Cura et al. 2010). In the Southern Cone region of South America, DTUs TcII, TcV and TcVI have been associated with most human $T$. cruzi infections. Chagasic cardiomyopathy can be severe and a proportion of cases may develop megaesophagus and megacolon (Zingales et al. 2012). TcIII is primarily associated with the silvatic cycle in Brazil and 
adjacent countries and documented human infections are rare. Human TcIV infections are sporadic in Venezuela and uncommon in other countries (Zingales et al. 2012).

DTUs and natural resistance to $B Z$ and $N F$ - No apparent DTU association with epimastigote natural resistance to BZ and NF has been observed, which is in contrast to reports for trypanocidal activities of novel macrolide antibiotics (Aquilino et al. 2012).

Drug screening capacity - In vitro drug screening capacity depends on many factors, mainly parasite stage used, length of assay, type of readout (image-based vs. colorimetric/fluorescence/luminescence-based) and, particularly, available equipment and resources. Although costly and available to few laboratories, high throughput screening currently provides the most sophisticated readout (Engel et al. 2010, Nohara et al. 2010). Genetically engineered parasites can offer improved read out of activities (Buckner et al. 1996).

Recommendations for the discovery and development of new drug candidates - By consensus, the authors recommend that surveys of new anti-trypanosomal candidates should consider the following guidelines:

(i) Screening should be performed on intracellular amastigotes. Epimastigote screening is much less expensive, but the results may be unrelated to efficacy against the amastigote stage. Differences in BZ and NF potency against axenic epimastigotes and intracellular stages have been reported (Neal \& van Bueren 1988). In amastigote screening, the infectivity and fitness of the clone/strain are the main factors behind the robustness and performance of the assay.

(ii) If resources allow, primary screens should ideally be performed against two clones/monoclonal strains. High throughput screening may be limited to a single clone/strain. Priority should be given to clones/strains belonging to DTUs more often associated with human infection ( $\mathrm{TcI}_{\mathrm{DOM}}, \mathrm{TcII}, \mathrm{TcV}$ and TcVI). The choice of biological clones is justified as they are genetically and phenotypically well-characterised organisms and constitute a more homogeneous population. A list of clones of different DTUs is available (Zingales et al. 2009). Laboratory strains displaying a monoclonal population structure may also be advantageous, as competition between clones of polyclonal strains is known to occur and clone selection may compromise assay performance and reproducibility.

(iii) Once promising drug candidates have been identified, they should be checked for broad activity against two or three representatives of each DTU (secondary screens). Priority should be given to DTUs that are more often associated with human infection $\left(\mathrm{TcI}_{\mathrm{DOM}}, \mathrm{TcII}\right.$, $\mathrm{TcV}$ and $\mathrm{TcVI}$ ), preferably with dissimilar characteristics regarding geographical origin, replication rates, as this parameter may impact the response to some classes of drugs, and level of susceptibility to BZ or NF. This last item is particularly relevant when any drug candidates are analogues of BZ and/or NF. An extensive list of strains reports susceptibility and natural resistance to the two drugs (Filardi \& Brener 1987). There is a large panel of clones representing the different DTUs, from which examples are available for comparison of in vitro drug susceptibility (Lewis et al. 2009, Moraes et al. 2014).

(iv) Genetically modified parasites may be used for drug screening if the genetic modification does not lead to major phenotypic changes compared to the parental clone/ strain. Transgenic strains expressing the Escherichia coli $\beta$-galactosidase gene, the firefly luciferase, the tandem tomato fluorescent protein and the green fluorescent protein are available (Buckner et al. 1996, Canavaci et al. 2010, Bustamante \& Tarleton 2011).

Concluding remarks - Activities regarding Chagas disease drug discovery depend largely on a limited number of academic groups. Consequently, little literature is available to support choices between models and different groups often rely on their own in vitro and in vivo models to discover and advance lead compounds and drug candidates. Here, we present an approach to the standardisation of one important aspect of Chagas disease drug discovery: the choice of $T$. cruzi strains and clones for in vitro screening. In vitro screens against a panel of strains and clones representing T. cruzi genetic diversity appear to be lacking in most Chagas disease drug discovery programmes, but we consider it to be a valuable component of the early assessment of promising drug candidates. However, we do not suggest that such comparisons of DTU susceptibilities must be performed before any evaluation of drug candidates in in vivo animal models. While the assessment of in vitro drug activity against members of different DTUs does not guarantee drug success in humans, divergent activities among the strains could indicate the likelihood of failure. Thus, screening against several parasite lineages would provide better grounds - but not necessarily a filter - for decisions on which compounds should and should not be advanced or how much further characterisation of a compound's anti-parasitic activity is needed before it can be advanced. Another advantage of performing in vitro assays is that they might allow a more straightforward evaluation of a strain/clone's "natural" resistance to a compound, as in vitro assays have fewer variables than in vivo models.

The vast majority of studies for in vivo drug screening use mouse models. Although the tools for in vivo screening have improved dramatically in the last few years (Bustamante \& Tarleton 2011), this system is impractical for the scrutiny of large compound libraries or analysis of the behaviour of several T. cruzi strains. Further validation of including representatives of the DTUs in in vitro assays of drug susceptibility testing will depend on the outcome of more in vitro studies, such as that of Moraes et al. (2014) and on focused and well controlled in vivo comparisons to increase understanding of the influence of $T$. cruzi genetic diversity on treatment outcome, which may be aided by in vivo bioluminescence imaging (Lewis et al. 2014).

In conjunction with high priority research on treatment for Chagas disease, the development of diagnostic tests for early determination of therapeutic responses and cure is urgently required (WHO 2012). A Strategic Translation Award from The Wellcome Trust is funding a three-year study to identify new biological mark- 
ers for the evaluation of therapeutic response in Chagas disease (Figure). The WHO, the Special Programme for Research and Training in Tropical Diseases and the PanAmerican Health Organization have sponsored an international study to evaluate polymerase chain reaction (PCR) methods detecting T. cruzi DNA in blood samples of patients with Chagas disease (Schijman et al. 2010). Further work is still needed to validate these methods through prospective studies in different settings, such as post-treatment follow-up. Nevertheless, alternatives to PCR are clearly needed.

Especially with the benefit of new drugs, international consensus is required to scale up diagnosis and treatment, to define criteria for treatment and to provide access to drugs. Currently, treatment coverage for Chagas disease patients is unacceptably low because many guidelines exclude chronic patients who are undoubtedly the most vulnerable majority.

For efficient R\&D, highly effective collaborations are required to optimise use of limited funding. Continued efforts to focus and improve drug discovery will greatly benefit both the research community and the population burdened with Chagas disease.

\section{ACKNOWLEDGEMENTS}

To DND $i$, for the opportunity to discuss the impact of the genetic diversity of $T$. cruzi on research and development of new treatments for Chagas disease during the Chagas Clinical Research Platform Meeting, and to Michael Lewis (LSHTM), for commenting on the text.

\section{REFERENCES}

Aquilino C, Gonzalez ML, Seco EM, Escudero L, Corvo L, Soto M, Fresno M, Malpartida F, Bonay P 2012. Differential trypanocidal activity of novel macrolide antibiotics; correlation to genetic lineage. PLoS ONE 7: e40901.

Benaim G, Sanders JM, Garcia-Marchán Y, Colina C, Lira L, Caldera AR, Payares G, Sanoja C, Burgos JM, Leon-Rossell A, Concepcion JL, Schijman AG, Levin M, Oldfield E, Urbina JA 2006. Amiodarone has intrinsic anti-Trypanosoma cruzi activity and acts synergistically with posaconazole. J Med Chem 49: 892-899.

Buckner FS 2011. Experimental chemotherapy and approaches to drug discovery for Trypanosoma cruzi infection. Adv Parasitol 75: 89-119.

Buckner FS, Verlinde CL, La Flamme AC, Van Voorhis WC 1996. Efficient technique for screening drugs for activity against Trypanosoma cruzi using parasites expressing beta-galactosidase. Antimicrob Agents Chemother 40: 2592-2597.

Bustamante JM, Craft JM, Crowe BD, Ketchie SA, Tarleton RL 2013. New, combined and reduced dosing treatment protocols cure Trypanosoma cruzi infection in mice. J Infect Dis 209: 150-162.

Bustamante JM, Tarleton RL 2011. Methodological advances in drug discovery for Chagas disease. Expert Opin Drug Discov 6: 653-661.

Canavaci AM, Bustamante JM, Padilla AM, Brandan CMP, Simpson LJ, Xu D, Boehlke CL, Tarleton RL 2010. In vitro and in vivo high-throughput assays for the testing of anti-Trypanosoma cruzi compounds. PLoS Negl Trop Dis 4: e740.

Cura CI, Mejia-Jaramillo AM, Duffy T, Burgos JM, Rodriguero M, Cardinal MV, Kjos S, Gurgel-Gonçalves R, Blanchet D, de Pablos LM, Tomasini N, Silva A, Russomando G, Cuba CA, Aznar C, Abate T, Levin MJ, Osuna A, Gürtler RE, Diosque P, Solari A,
Triana-Chávez O, Schijman AJ 2010. Trypanosoma cruzi I genotypes in different geographical regions and transmission cycles based on a microsatellite motif of the intergenic spacer of spliced leader genes. Int J Parasitol 40: 1599-1607.

Diniz LF, Urbina JA, de Andrade IM, Mazzeti AL, Martins TAF, Caldas IS, Talvani A, Ribeiro I, Bahia MT 2013. Benznidazole and posaconazole in experimental Chagas disease: positive interaction in concomitant and sequential treatments. PLoS Negl Trop Dis 7: e2367.

DND $i$ - Drugs for Neglected Diseases initiative 2013. Proof of concept study of E1224 to treat adults patients with Chagas disease. Available from: clinicaltrials.gov/ct2/show/NCT01489228?term= chagas + disease $\&$ rank $=9$.

Engel JC, Ang KK, Chen S, Arkin MR, McKerrow JH, Doyle PS 2010. Image-based high-throughput drug screening targeting the intracellular stage of Trypanosoma cruzi, the agent of Chagas disease. Antimicrob Agents Chemother 54: 3326-3334.

Filardi LS, Brener Z 1987. Susceptibility and natural resistance of Trypanosoma cruzi strains to drugs used clinically in Chagas disease. Trans R Soc Trop Med Hyg 81: 755-759.

Guhl F, Ramírez JD 2011. Trypanosoma cruzi I diversity: towards the need of genetic subdivision? Acta Trop 119: 1-4.

Lewis MD, Fortes FA, Taylor MC, Burrell-Saward H, McLatchie AP, Miles MA, Kelly JM 2014. Bioluminescence imaging of chronic Trypanosoma cruzi infections reveals tissue-specific parasite dynamics and heart disease in the absence of locally persistent infection. Cell Microbiol doi: 10.1111/cmi.12297.

Lewis MD, Llewellyn MS, Gaunt MW, Yeo M, Carrasco HJ, Miles MA 2009. Flow cytometric analysis and microsatellite genotyping reveal extensive DNA content variation in Trypanosoma cruzi populations and expose contrasts between natural and experimental hybrids. Int J Parasitol 39: 1305-1317.

Miles MA, Llewellyn MS, Lewis MD, Yeo M, Baleela R, Fitzpatrick S, Gaunt MW, Mauricio IL 2009. The molecular epidemiology and phylogeography of Trypanosoma cruzi and parallel research on Leishmania: looking back and to the future. Parasitology 136: 1509-1528.

Molina I, Prat JG, Salvador F, Treviño B, Sulleiro E, Serre N, Pou D, Roure S, Cabezos J, Valério L, Blanco-Grau A, SánchezMontalvá A, Vidal X, Pahissa A 2014. Randomized trial of posaconazole and benznidazole for chronic Chagas' disease. $N$ Engl $J$ Med 370: 1899-1908.

Moraes CB, Giardini M, Kim H, Franco CH, Araujo-Junior AM, Schenkman S, Chatelain E, Freitas-Junior LH 2014. Nitroheterocyclic compounds are more efficacious than CYP51 inhibitors against Trypanosoma cruzi: implications for Chagas disease drug discovery and development. Sci Rep 4 doi: 10.1038/srep04703.

Neal RA, van Bueren J 1988. Comparative studies of drug susceptibility of five strains of Trypanosoma cruzi in vivo and in vitro. Trans R Soc Trop Med Hyg 82: 709-714.

Nohara LL, Lema C, Bader JO, Aguilera RJ, Almeida IC 2010. Highcontent imaging for automated determination of host-cell infection rate by the intracellular parasite Trypanosoma cruzi. Parasitol Int 59: 565-570.

Rassi Jr A, Rassi A, de Rezende JM 2012. American trypanosomiasis (Chagas disease). Infect Dis Clin N Am 26: 275-291.

Schijman AG, Bisio A, Orellana L, Sued M, Duffy T, Mejia-Jaramillo AM, Cura C, Auter F, Veron V, Qvarnstrom Y, Deborggraeve S, Hijar G, Zulantay I, Lucero RH, Velazquez E, Tellez T, Leon ZS, Galvão L, Nolder D, Rumi MM, Levi JE, Ramirez JD, Zorrilla P, Flores M, Jercic MI, Crisante G, Añez N, de Castro AM, Gonzalez CI, Viana KA, Yachelini P, Torrico F, Robello C, Diosque 
P, Chavez OT, Aznar C, Russomando G, Büscher P, Assal A, Guhl F, Sosa-Estani S, da Silva A, Britto C, Luquetti A, Ladzins J 2010. International study to evaluate PCR methods for detection of Trypanosoma cruzi DNA in blood samples from Chagas disease patients. PLoS Negl Trop Dis 5: e931.

Schofield CJ, Jannin J, Salvatella R 2006. The future of Chagas disease control. Trends Parasitol 22: 583-588.

Sosa-Estani S, Viotti R, Segura EL 2009. Therapy, diagnosis and prognosis of chronic Chagas disease: insight gained in Argentina. Mem Inst Oswaldo Cruz 104 (Suppl. I): 167-180.

Tibayrenc M 1998. Genetic epidemiology of parasitic protozoa and other infectious agents: the need for an integrated approach. Int $J$ Parasitol 28: 85-104.

Urbina JA 2010. Specific chemotherapy of Chagas disease: relevance, current limitations and new approaches. Acta Trop 115: 55-68.

Vago AR, Andrade LO, Leite AA, Reis DD, Macedo AM, Adad SJ, Tostes S, Moreira MC, Filho GB, Pena SD 2000. Genetic characterization of Trypanosoma cruzi directly from tissues of patients with chronic Chagas disease: differential distribution of genetic types into diverse organs. Am J Pathol 156: 1805-1809.

WHO - World Health Organization 2012. Research priorities for Chagas disease, human African trypanosomiasis and leishmaniasis. Available from: apps.who.int/iris/bitstream/10665/77472/1/ WHO_TRS_975_eng.pdf.

WHO - World Health Organization 2013. Chagas disease (American trypanosomiasis). Available from: who.int/mediacentre/factsheets/fs340/en/.

Zingales B, Andrade SG, Briones MRS, Campbell DA, Chiari E, Fernandes O, Guhl F, Lages-Silva E, Macedo AM, Machado CR, Miles MA, Romanha AJ, Sturm NR, Tibayrenc M, Schijman AG 2009. A new consensus for Trypanosoma cruzi intraspecific nomenclature: second revision meeting recommends TcI to TcVI. Mem Inst Oswaldo Cruz 104: 1051-1054.

Zingales B, Miles MA, Campbell DA, Tibayrenc M, Macedo AM, Teixeira MMG, Schijman AG, Llewelly MS, Lages-Silva E, Machado CR, Andrade SG, Sturm NR 2012. The revised Trypanosoma cru$z i$ subspecific nomenclature: rationale, epidemiological relevance and research applications. Infect Genet Evol 12: 240-253. 
Chagas Disease Drug Discovery and Development Landscape

\begin{tabular}{|c|c|c|c|c|c|c|c|c|}
\hline \multicolumn{3}{|c|}{ Research } & \multicolumn{3}{|c|}{ Translational } & \multicolumn{3}{|c|}{ Development } \\
\hline Screen & Hit to Lead & Lead Opt. & $\begin{array}{c}\begin{array}{c}\text { Pre- } \\
\text { clinical }\end{array} \\
\end{array}$ & Phase I & \begin{tabular}{|c|} 
Phase lla / \\
Poc
\end{tabular} & Phase IIb/III & Registration & Implem. \\
\hline $\begin{array}{c}\text { GSK } \\
\text { Tres Cantos } \\
\end{array}$ & & $\begin{array}{c}\text { GNFI } \\
\text { Washingtion } \\
\text { Univerity }\end{array}$ & $\begin{array}{l}\text { BERENICE } \\
\text { Consortirum }\end{array}$ & & $\begin{array}{c}\text { Posacanoazole } \\
\text { (Merck) }\end{array}$ & $\begin{array}{l}\text { TRAENA } \\
\text { BENEFIT }\end{array}$ & $\begin{array}{c}\text { Adult } \\
\text { Benznidazole }\end{array}$ & $\begin{array}{c}\text { Pediatric } \\
\text { Nifurtimox }\end{array}$ \\
\hline 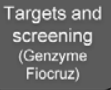 & $\begin{aligned} \begin{array}{l}\text { Series } 5 \\
\text { (Epichem) }\end{array} \\
\text { Broad series }\end{aligned}$ & $\begin{array}{l}\text { Broad series } \\
1+2\end{array}$ & $\begin{array}{c}\begin{array}{c}\text { Fenarimol } \\
\text { Backups }\end{array} \\
\text { K }\end{array}$ & & Fexinidazole & & & $\begin{array}{c}\text { Pediatric } \\
\text { Benznitazole } \\
\text { (AFFEFE) }\end{array}$ \\
\hline $\begin{array}{l}\text { Chagas DD DD } \\
\text { Consontum } \\
\text { Bionakikers } \\
\text { (UGANYUU) }\end{array}$ & 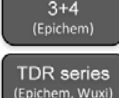 & 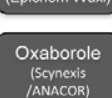 & & & $\begin{array}{c}\text { Sparing } \\
\text { Regimens } \\
\text { inination }\end{array}$ & & & $\begin{array}{l}\text { Pediatric } \\
\text { Benznidizale } \\
(E[E A)\end{array}$ \\
\hline GNF & & & & & tment & & & \\
\hline Eisail/Broad & & $\begin{array}{c}\text { Nitroimid- } \\
\text { azoles }\end{array}$ & & Biomarke: & & & & \\
\hline $\begin{array}{l}\text { LSTMH } \\
\text { STPH }\end{array}$ & & & & & & & & \\
\hline $\begin{array}{l}\text { IPK } \\
\text { Dundiee } \\
\text { Eskitis }\end{array}$ & & & & & & & & \\
\hline $\begin{array}{l}\text { Northshore } \\
\text { University }\end{array}$ & & & & & & & & \\
\hline $\begin{array}{l}\begin{array}{l}\text { DDU @ } \\
\text { Dundee }\end{array} \\
\end{array}$ & & Projec & IDi colla & n/coord & & & & \\
\hline
\end{tabular}

Chagas Disease Drug Discovery and Development Landscape

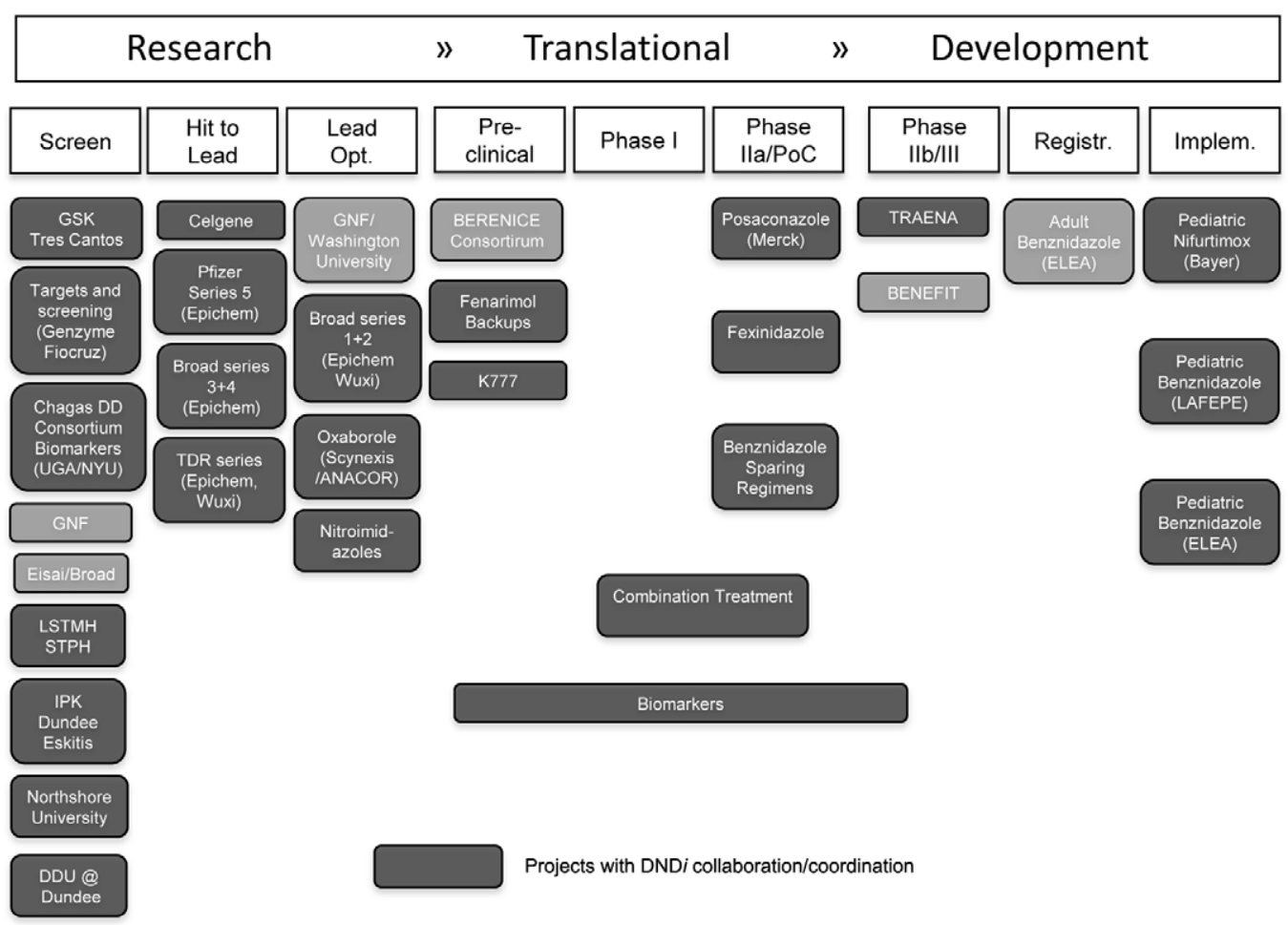

Chagas disease drug discovery and development landscape in 2013/2014. Research activities: public and private partners are engaged in the screening of chemical libraries, hit to lead and lead optimisation of new series for Chagas disease treatment; Translational activities: pre-clinical studies, Phase I and IIa studies with new compounds are underway; Development activities: two double-blind, placebo-controlled clinical trials are testing the potential beneficial effects of benznidazole (BZ) in chronic Chagas disease. The Argentine company Elea Laboratories is manufacturing the generic version of BZ under the tradename Abarax. Paediatric formulations of BZ and nifurtimox are being implemented. BENEFIT: Benznidazole Evaluation for Interrupting Trypanosomiasis; BERENICE: Benznidazole and Triazole Research Group for Nanomedicine and Innovation on Chagas Disease; Broad: Broad Institute; DDU@Dundee: Drug Discovery Unit at Dundee University; DNDi: Drugs for Neglected Diseases initiative; GNF: Genomics Institute of the Novartis Research Foundation; IPK: Institute Pasteur Korea; LSTMH: London School of Tropical Medicine \& Hygiene; NYU: New York University; STPH: Swiss Tropical and Public Health Institute; TRAENA: Tratamiento con Benznidazol en pacientes Adultos con Enfermedad de Chagas Crónica; UGA: University of Georgia. 